\title{
An online interactive tool to assess energy consumption in residential buildings and for daily mobility
}

\author{
Anne-Françoise Marique ${ }^{\mathrm{a}, *}$, Tatiana de Meester ${ }^{\mathrm{b}}$, André De Herde ${ }^{\mathrm{b}}$, Sigrid Reiter ${ }^{\mathrm{a}}$ \\ a Local Environment: Management E' Analysis (LEMA), University of Liège Chemin des Chevreuils, 1 B52/3 4000 Liege Belgium \\ ${ }^{\mathrm{b}}$ Architecture et Climat, Université catholique de Louvain Place du Levant, 11348 Louvain-La-Neuve Belgium
}

\section{A R T I C L E I N F O}

\section{Article history:}

Received 24 October 2013

Received in revised form 3 March 2014

Accepted 7 April 2014

Available online 19 April 2014

\section{Keywords:}

Occupant behaviour

Energy efficiency

Building energy consumption

Daily mobility

Interactive tool

Assessment methods

\begin{abstract}
A B S T R A C T
Improving energy efficiency in the building and transportation sectors is a viable approach to mitigate the effects of climate change and has become an important policy target. As a result, in addition to scientific research and public policies addressing energy efficiency, raising public awareness of the impact of the behaviour of citizens to energy efficiency is crucial and could quickly lead to significant reductions in the total energy consumption of a territory. In this context, this paper presents a new online interactive tool that enables not only citizens but also local authorities and private developers to (1) assess the sources of energy consumption related to housing and to daily mobility at both the individual and neighbourhood scales, (2) compare these sources and (3) determine relevant and personalised suggestions to reduce energy consumption. Numerous methods and tools, including a typological classification of buildings, thermal dynamic simulations, life-cycle assessments and statistical treatments of national censuses, were used to produce the two large databases used in this interactive tool. This report represents the primary results of a three-year long scientific research project dedicated to the study of energy efficiency in buildings and for daily mobility that is accessible to a large non-specialised audience.
\end{abstract}

(C) 2014 Elsevier B.V. All rights reserved.

\section{Introduction}

\subsection{Context and literature review}

As environmental issues are of increasing interest, reducing energy consumption in the building and transportation sectors has become as an important policy target $[1,2]$. The building and transportation sectors respectively represent $40 \%$ and $32 \%$ of the final primary energy consumed in Europe [3]. As a result, energy efficiency in the building and transportation sectors has been the focus of extensive world-wide research over the past decades. Numerous research studies describe the use of mathematical models and simulation tools as the most credible approach to model the behaviour and to predict the energy consumption of a system, in terms of global sustainability. Thus, a huge number of models, tools and papers [e.g., 4-11] address energy efficiency and, most of them focus on the heating requirements of residential or tertiary buildings at the individual building scale. More recently, the literature has increasingly revealed that the decisions made

\footnotetext{
* Corresponding author. Tel.: +32 43669367; fax: +32 43662909

E-mail address: afmarique@ulg.ac.be (A.-F. Marique).
}

at the neighbourhood level have important consequences on the performance of individual buildings and energy efficiency at the district scale and at the city scale [e.g., 12-16]. The role that the urban form plays in influencing the choice of travel modes and the energy consumption of transport has also been studied extensively [e.g., 17-20]. Mathematical models, namely those based on empirical data and/or predictions, have thus been developed and used to assess energy consumption and/or greenhouse gas emissions due to the mobility of individuals at the neighbourhood, city and regional scales $[21,22]$. Amongst their numerous advantages, the approaches based on mathematical models and simulation tools can account for a large number of parameters that are known to act upon the energy consumptions of a system and to perform parametric variations to test the impact of several energy efficiency strategies.

Although several research and empirical results have demonstrated the significant impact of the behaviour of housing occupants on energy consumption [e.g., 23, 24], these results and findings remain mainly concentrated in the academic and scientific fields, whereas citizens, authorities and policy makers are the first actors that can concretely act to alter the energy consumption in residential buildings and for daily mobility. The implementation of energy efficiency measures into concrete policies and to the general public (citizens, local authorities, policy makers, etc.) are thus crucial to 
ensure a more sustainable development of our territories and to reduce energy consumption.

For example, regarding the regulation framework, the famous Directive on the Energy Performance of Buildings that was implemented in 2002 in Europe is a first interesting step towards enhancing energy efficiency in the building sector. The main aim of the Directive is to establish minimum standards on the energy performance of new buildings and existing buildings larger than $1000 \mathrm{~m}^{2}$ that are subject to major renovation [25]. However, this Directive still adopts the perspective of the individual building as being an autonomous entity and neglects both the importance of phenomena linked to larger scales and the energy consumption of the existing building stock. Research dealing with an energy assessment of building energy consumption combined with an assessment of the impact of the house location on the energy consumption due to daily mobility are not numerous, even though daily mobility has been proven to be of crucial importance in the total energy balance of a household [15]. In general, the impact of location on the energy consumption for daily mobility remains less considered by households and in current policies, particularly in comparison with land prices, although a significant rise in the cost of oil and petrol make this factor an increasingly considerable part of their budget (especially in suburban neighbourhoods).

On the whole, three main challenges highlighted in the literature are often neglected or considered individually: (1) the major challenge of the retrofitting of existing building stock; (2) the importance of the location of residences, work places and services in the generation of mobility patterns and, above all, (3) the impact of the lifestyles and behaviours of citizens on the energy consumption in both sectors. Raising public awareness of these challenges of energy efficiency and providing not only citizens but also local authorities and policy makers with practical advice adapted to their own situation is thus crucial. This could lead to significant reductions in the total energy consumption of a territory, particularly for both building and transportation energy consumption.

\subsection{Aim of the study}

In this context, this paper presents an online interactive tool dedicated to the energy assessment of the building and transportation sectors, in Wallonia (Belgium), at the individual, household and neighbourhood scales. The main aim of this online interactive tool is to make available to citizens and local stakeholders numerous results of a scientific research (e.g., more than 180,000 results of dynamic thermal simulations are made available) in a very simple form. It addresses one major shortcoming of existing tools: the accessibility to citizens and local stakeholders. In fact, although simulation programs (BPS tools) dedicated to energy efficiency in buildings are numerous (e.g., TRNSYS, Comfie + Pleiades, Energyplus, phpp) and have remarkable capabilities, user-friendly assessment tools dedicated to a non-specialised audience (local authorities, developers, citizens) and ready-to-use applications are lacking $[26,27]$. Most of the existing tools are designed by engineers for use by other trained engineers, which make them too complicated to quickly evaluate the performance of different design concepts or strategies [28]. Amongst the existing simplified evaluation tools, Attia et al. [27] developed a simulation-based decision support tool for early stages of zero-energy building design and highlighted the need to integrate energy simulation into early design of buildings. Gratia and De Herde developed a simple design tool for the thermal study of dwellings [8] and office buildings [9]. The calculation of the energy consumption is mainly dedicated to architects and based on the results of dynamic thermal software. Amongst others, Praznic et al. [29] and Reilly et al. [30] developed simplified method for energy efficiency in building. Their aim was to use as few parameters as possible and simple calculation method. Zhao and Magoules [31] reviewed recently developed models to simply and accurately predict building energy consumption (e.g., engineering methods, statistical methods, artificial intelligence). They concluded, from their analysis, that numerous models exist with their own advantages and disadvantages and that a complete comparison, under the same conditions, is needed. The use of these tools by citizens is not addressed. O'Lonney [32] developed a decision support tool for citizens and policy makers whose aim is to assist citizens to be more knowledgeable in a sustainable built environment. This tool links land use planning choices with cost estimations and several types of impacts but do not address energy efficiency in buildings and for transportation.

\subsection{Rationale and content of the online interactive tool}

The rationale of the online interactive tool is thus to provide not only Walloon citizens and households but also private developers, architects and local authorities with a simple, accurate and quick assessment of energy efficiency in both the residential building stock as well as for daily mobility, at the individual, household and neighbourhood scales.

This tool makes accessible to a large non-specialised audience the results of a three-year scientific research study that combined numerous tools and data (a geographic information system, a typological classification of buildings and neighbourhoods, a dynamic thermal simulation software, life-cycle assessments, statistical analyses of national censuses, etc.) in Wallonia (Belgium). Thanks to this tool, numerous data, algorithms and results related to transportation energy consumption (stored in database 1) as well as the results of over 180,000 thermal simulations of buildings (stored in database 2) are made available online. To ensure widespread diffusion of the research study results, the online interactive tool was designed to be user-friendly, to require a minimum of input data while providing accurate results, to be very easy to learn and use and to be easily available and for free on the web (www.safe-energie.be). This tool is available only in French in this first version (see Section 4 for more details on the current features provided to the tool).

Regarding its content, the online interactive tool comprises three interactive evaluation tools dedicated to the assessment of energy consumption for the heating of buildings and for daily mobility ((1) a simplified evaluation, (2) a detailed evaluation and (3) a neighbourhood evaluation; these evaluation tools give access to the research results stored in two huge database (the first one dedicated to transportation energy consumption and the second one to building energy consumption), general information about the research project dedicated to energy efficiency and eighteen specification sheets, organised into four main sections (general information, energy efficiency and buildings, energy efficiency and daily mobility, energy efficiency and urban form). Fig. 1 summarises the architecture of the online interactive tool.

\subsection{Structure of the paper}

Section 2 describes the methodology and the assumptions that were used to develop the tool. Its contents (the three dynamic evaluation tools and the guidelines) are presented, described and illustrated in Section 3. The limitations and the reproducibility of this approach are discussed and summarised in Section 4. Section 5 summarizes our main findings.

\section{Methodology}

The method used to developed the two databases used by the three evaluation tools includes two main parts: (1) an empirical 


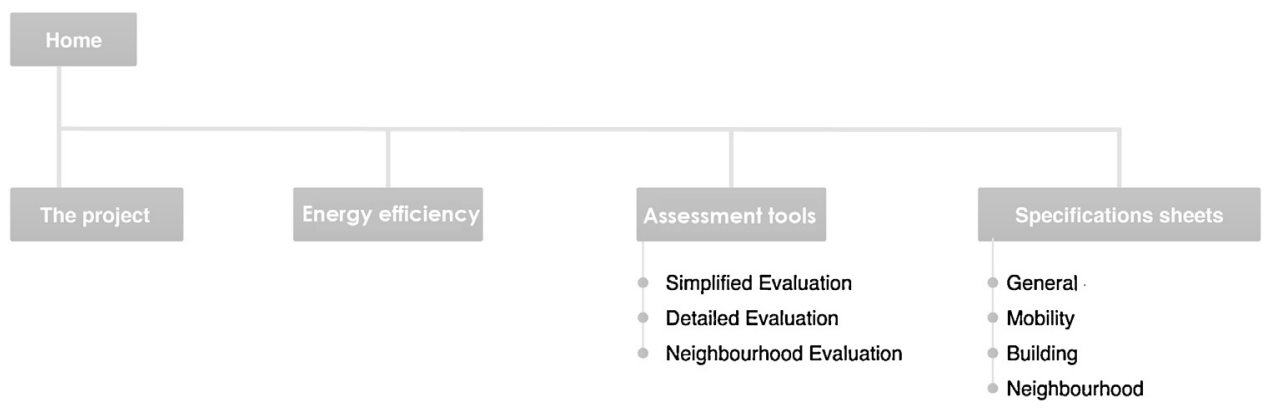

Fig. 1. Architecture of the online interactive tool.

approach to assess the energy consumed for daily mobility and (2) a computational approach combining dynamic simulation tools, lifecycle assessments and a database of building and neighbourhood typologies to determine the energy consumed in the heating and ventilation of buildings.

\subsection{Energy consumption for daily mobility}

\subsubsection{Method}

A quantitative method was developed to assess energy consumption for daily mobility. The complete method and data set were presented in detail in two previous papers addressing the investigation of the relationships between the urban form the location of the activities in the territory and the transportation energy consumption for home-to-work and home-to-school travels $[33,34]$.

Three indices were derived from this general method to be used in the three interactive evaluation tools. The energy performance index (expressed in $\mathrm{kWh} /$ travel person) for a defined unit (a city, a neighbourhood, a household or a person) represents the mean energy consumption for home-to-destination travels for one person living within the considered unit. This index takes into account the distances travelled, the means of transport used and their relative consumption rates, as expressed by Eq. (1). In the equation, $i$ represents the territorial unit; $m$ is the means of transport used (diesel car, fuel car, train, bus, bike, on foot); Dmi is the total distance travelled by the means of transport $m$ in the district i for home-to-destination travels; $\mathrm{fm}$ is the consumption factor attributed to means of transport $\mathrm{m}$ and $\mathrm{Ti}$ is the number of travellers living in the territorial unit i.

Energy performance index $(i)=\left(\sum m D m i * f m\right) / T i$

The consumption factors fm were calculated by [22] on the basis of regional and local data. The consumption factors are $0.56 \mathrm{kWh} /$ person $\mathrm{km}$ for a diesel car, $0.61 \mathrm{kWh} / \mathrm{p} \mathrm{km}$ for a fuel car, $0.45 \mathrm{kWh} / \mathrm{p} \mathrm{km}$ for a bus, $0.15 \mathrm{kWh} / \mathrm{p} \mathrm{km}$ for a train and 0 for a non-motorised means of transportation (because these do not consume any energy). Electric and LPG cars are not taken into account because these cars not numerous in Belgium. Related consumption factors could be calculated in the future to include these cars in the assessments.

The distance index (in $\mathrm{km}$ ) represents the mean home-todestination distance travelled (one way) by one person. The modal share index (in \%) represents the frequency of use for each means of transportation per territorial unit. The annual energy efficiency of the travels can finally be expressed in kWh per year to enable a comparison between the energy consumption for daily mobility and the energy consumption in the residential building sector (heating, appliances, electricity, etc.).

\subsubsection{Input data and storage of the results}

The input data used in the three methods of evaluation provided in the online interactive tool are obtained from either national census (the General Socio-Economic Survey 2001 [35]) results (in the simplified evaluation and in the neighbourhood evaluation) or directly from the users (in the detailed evaluation). In the latter case (see also Section 3.3 for more details), the calculation of the index is entirely parameterised to enable easy adaptation to the data of the users (e.g., consumption of the car of the user and chained trips). The algorithms and factors are stored in the first database. Note that energy consumption for heating buildings are also converted into $\mathrm{CO}_{2}$ emissions to complete the approach proposed in the tool.

\subsection{Energy consumption in buildings}

The second part of the method is dedicated to determining the energy requirements for the heating and ventilation of buildings (cooling needs are not taken into account because these are minimal in Belgium). Local empirical surveys [36-38] have indicated that heating represents the largest part of the overall energy consumption of Belgian households (76\%), with home appliances, production of hot water and cooking representing $10 \%, 11 \%$ and $3 \%$ of the overall household energy consumption, respectively, are not taken into account in the first version of the tool (see also Section 4).

\subsubsection{Typological classification of buildings}

A typology of detached, semi-detached and terraced houses was established to classify the residential building stock of Wallonia (Belgium). The typology covers, for the moment, only single-family buildings because the research project was dedicated to urban sprawl, which is, in this region, predominantly residential. This typological approach, also used by $[1,14,16]$, is based on the following factors: common ownership, the area of the house in square meters $\left(\mathrm{m}^{2}\right)$, the number of levels and the date of construction. The type of building determines the percentage of openings in the walls (windows) and the proportions of the building. Seventy-two general types of buildings are used in this typology. Five age categories (pre-1950, 1951-1980, 1981-1995, 1996-2011, post 2011) are considered, based on the evolution of regional policies concerning building energy performance and the evolution of construction techniques. These age categories are used to approximate a mean thermal conductivity of the external façades from a "standard" composition of façades and glazing attributes for the buildings in each category (Table 1 ) and the regulations requirements during these periods $[25,41,42]$. Three additional categories are added for houses built according to standards higher than the European Energy Performance of Buildings Directive (EPBD). These are the low-energy standard, the very low-energy standard and the passive standard, which correspond to annual heating requirements lower than $60 \mathrm{kWh} / \mathrm{m}^{2}$ year, $30 \mathrm{kWh} / \mathrm{m}^{2}$ year and $15 \mathrm{kWh} / \mathrm{m}^{2}$ year, 
Table 1

Characteristics of external façades and glazing by age category ( $U=$ heat transfer coefficient, $\mathrm{W} / \mathrm{m}^{2} \mathrm{~K}$ ).

\begin{tabular}{|c|c|c|c|c|c|}
\hline & Pre-1950 & 1951-1980 & 1981-1995 & 1996-2011 & Post 2011 \\
\hline Wall $U$ & $U=2.5$ & $U=2.5$ & $U=0.9$ & $U=0.5$ & $U=0.4$ \\
\hline Roof $U$ & $U=1.9$ & $U=1.9$ & $U=1.1$ & $U=0.6$ & $U=0.3$ \\
\hline Slab $U$ & $U=1.9$ & $U=1.9$ & $U=0.9$ & $U=0.5$ & $U=0.4$ \\
\hline Glazing type & Simple glazing & Old double gl. & Old double gl. & Double glazing & Double glazing \\
\hline Glazing $U$ & 5.8 & 2.8 & 2.8 & 1.1 & 1.1 \\
\hline
\end{tabular}

respectively. These standards must achieve a specific performance objective. Therefore, these standards were not simulated, but the requirement is imposed on all types of buildings, regardless of the implemented insulation thickness. The requirement and the selected heating system or auxiliary heating determine the heating demand.

\subsubsection{Parameters of the main types of buildings}

Parameters of these main types of buildings were then defined and studied to take into account retrofitting work performed by owners (for example, to provide results for a house built before 1984 (and thus not insulated) in which simple glazing was replaced by double glazing and the roof was insulated with $12 \mathrm{~cm}$ of mineral wool). These parameters concern the level of insulation in the walls, roofs and slabs, the types of glazing, the ventilation system and the choice of the thermostat.

\subsubsection{Thermal simulations and main assumptions}

Using the classifications of buildings (main types + parameters), an energy consumption analysis is performed using thermal simulation software [43] that includes a three-dimensional modeller and an interface for the input of the thermal information (climate conditions, building materials, internal conditions, periods of use of the house, etc.) for each possible type of building. The amount of energy required to heat each type of building was modelled.

In these simulations, we used the Belgian climate (temperate climate of the northern part of Europe). The meteorological data of Brussels were used. The data comprised the hourly data of the temperature, humidity, global solar radiation, diffuse solar radiation, cloud cover, dry bulb temperature, wind speed and wind direction [44]. The mean temperature for a typical year used in the simulations was $10.3^{\circ} \mathrm{C}$. The maximum and minimum temperatures, for the considered year were $34.9{ }^{\circ} \mathrm{C}$ and $-9.1^{\circ} \mathrm{C}$. To adjust the results to the localisation of the selected house, the results presented in the tool are adapted to the degree-day place.

Internal gains were defined according to the housing size. The size determines the number of occupants, the number of rooms, etc. In the house, internal gains are adapted to the function of the room. This ability to adapt is enabled by the use of multi-zone simulations that account for any overheating phenomena, which are neglected in monozone simulations. The modelling of the internal gains took into account the source of heat inside the building, which is essential in analytical work at different levels of energy performance because these internal gains can be the source of overheating in the building especially when it is well insulated. The more efficient the building is, the greater is the influence of internal gains on the heating energy consumption of the building. The total internal gains used in each thermal simulation depend on the chosen occupation mode and thus on combinations of the treated parameters. The reference value comes from a monitoring measurement and has a value of $2.57 \mathrm{~W} / \mathrm{m}^{2}$ [39].

The heat emissions used in the simulations are presented in Table 2 [39-42,45,47].

These internal gains are distributed among the different zones of the dwelling. From the zones, occupation will result in lighting, the use of television or computer and cooking. These internal gains are set on one day and are assumed to be constant throughout the week and the year. The modelling of the internal gains does not take into account holidays.

Two systems of thermostats were proposed: a constant temperature of $20^{\circ} \mathrm{C}$ in the house (note that $20^{\circ} \mathrm{C}$ is the temperature imposed in the Belgian EPB software [46]) and a temperature of $20^{\circ} \mathrm{C}$ from 6 am to 8 am and from 5 pm to midnight, with a drop in temperature to $16^{\circ} \mathrm{C}$ at night and during office hours. These two types of thermostats are defined to ensure thermal comfort.

Concerning the ventilation system, the mechanical ventilation system is modeled on the heating system. Mixed-mode ventilation (with mechanical exhaust) and mechanical ventilation systems function when the house is occupied [47]. The natural ventilation corresponds to the opening of the windows but that can vary greatly depending on size of windows and buildings and also depending on inhabitants. To propose a ventilation rate proportional to each type of house, natural ventilation rates correspond to those of the mixedmode ventilation but the difference is that mixed-mode ventilation uses electricity. These rates were calculated using a Belgian requirement [41].

To convert the energy needs for heating into energy consumption, 23 heating systems were defined (either local or central). The overall performance of these 23 heating systems was applied to the annual heating need of the considered house. The efficiency of each 23 heating systems was defined on the basis of Annex I of the Walloon Decree on the energy performance of buildings [46]. Primary energy is provided in the results to raise public awareness of the impact of the heating system on the environment. Note that the amounts of energy consumption for heating buildings are also converted into $\mathrm{CO}_{2}$ emissions to complete the approach proposed in the tool, via the conversion factors $[48,49]$.

\subsubsection{Storage of the results}

A large database (database 2) was finally built to store the numerous results of the thermal simulations applied to each type of main building and its parameters (Table 3 ). The database comprises the results of over 180,000 thermal simulations related to building energy consumption. A unique code is attributed to each possible combination of parameters to link the data introduced by the user in the questionnaire with the results provided in the database.

\section{Table 2}

Heat emissions used in the simulations [39-42,45,47].

\begin{tabular}{ll}
\hline Type & Heat emissions \\
\hline Occupation & $80 \mathrm{~W}$ per person; the number of persons varies \\
& $\begin{array}{l}\text { from } 0 \text { to } 5 \text { according to the occupation mode } \\
0.85 \mathrm{kWh} / \text { day }\end{array}$ \\
$\begin{array}{l}\text { Refrigeration and deep } \\
\text { freeze }\end{array}$ & $0.3 \times 1.1 \mathrm{kWh} / \mathrm{use}$ (on a basis of 65 \\
Washing-up & uses/year person) \\
& $50 \mathrm{kWh} /$ year person \\
Appliances & $150 \mathrm{~W}(1,2$ or $3 \mathrm{~h} /$ day $)$ \\
Television & $70 \mathrm{~W}(0,1,2$ or $10 \mathrm{~h} /$ day $)$ \\
Computer use & $912 \mathrm{~W}(0.5,1$ or $1.5 \mathrm{~h} /$ day $)$ \\
Cooking & $6 \mathrm{~W} / \mathrm{m}^{2}$ \\
Lighting & $1486 \mathrm{~W} /$ shower $(0,24$ or $48 \mathrm{~min} /$ day $)$ \\
Shower &
\end{tabular}




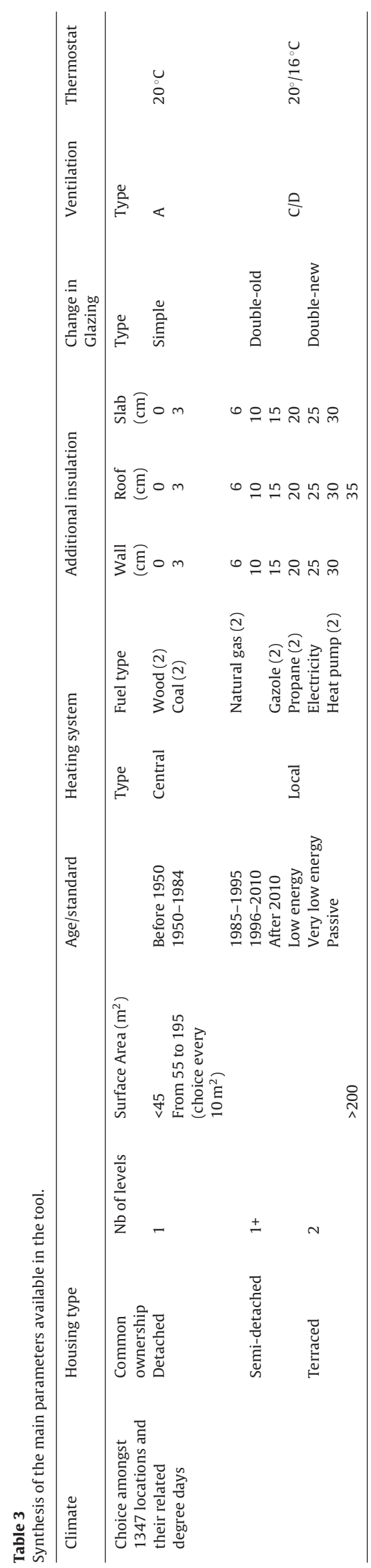

\subsection{Validation and relevance of the results}

The methods and data used to build the databases were presented extensively in previous papers $[15,22]$. The software used in the analysis have namely been validated by the International Energy Agency Bestest [50]. We also used the second database (building energy consumption) presented in this paper to calculate the energy consumption of the whole building stock of Wallonia and compared this result with a survey ("annual thermal survey") carried out by ICEDD [36] on the basis of real consumption of Walloon households. Difference between the two results is worth $8.2 \%$ which was considered as acceptable.

\section{Results: the three evaluation tools}

\subsection{Structure of the evaluation tools}

The main aims of these three evaluation tools were determined by the research team together with the sponsor of the research project (regional authority in charge of energy efficiency, sustainable buildings and urban planning). The three goals were (1) the assessment of energy consumption for heating and ventilating building(s) and for daily mobility to take into account in the total energy balance the impact of the location on the energy consumption for transportation, (2) the comparison between the energy used in the building and in the transportation sectors and, (3) the proposition of practical and personalised recommendations to reduce the energy balance of the user. The potential energy savings related to several concrete scenarios are quantified, which allows the user to choose the most efficient scenario in its specific case. The two first evaluations (simplified evaluation and detailed evaluation) are dedicated to citizens, and the last one (neighbourhood evaluation) is for developers, architects and local authorities.

Each evaluation tool is structured around the following four steps (see also Fig. 2):

1. An assessment of the transportation habits of the users for hometo-work and home-to-school travels (step 1);

2. An assessment of the energy consumption of heating of the user's house (step 2):

3. The comparison of the annual energy consumption and $\mathrm{CO}_{2}$ emissions for heating the house and for transportation and (step 3);

4. The propositions, on the basis of the previous results, of practical and personalised recommendations to reduce the energy consumption. These propositions come with a quantitative assessment of the potential energy savings to allow the user to choose the most adapted ones for each specific case (step 4).

The assessments are realised on the basis of questionnaires specific to each evaluation. Data that are introduced in the questionnaire by the user are sent to the corresponding database (database 1 is dedicated to transport energy consumption, database 2 is dedicated to building energy consumption). The corresponding results are re-sent to the website and posted. The three evaluation tools, their aims and the users to which the results are addressed are presented in the following sections. The next section presents the sheets of specifications (guidelines) that provide the tool with practical information about energy efficiency.

\subsection{The simplified evaluation}

The simplified evaluation allows an individual user (or household) to assess the energy consumption for daily mobility (only home-to-work and home-to-school travels in this evaluation) and 


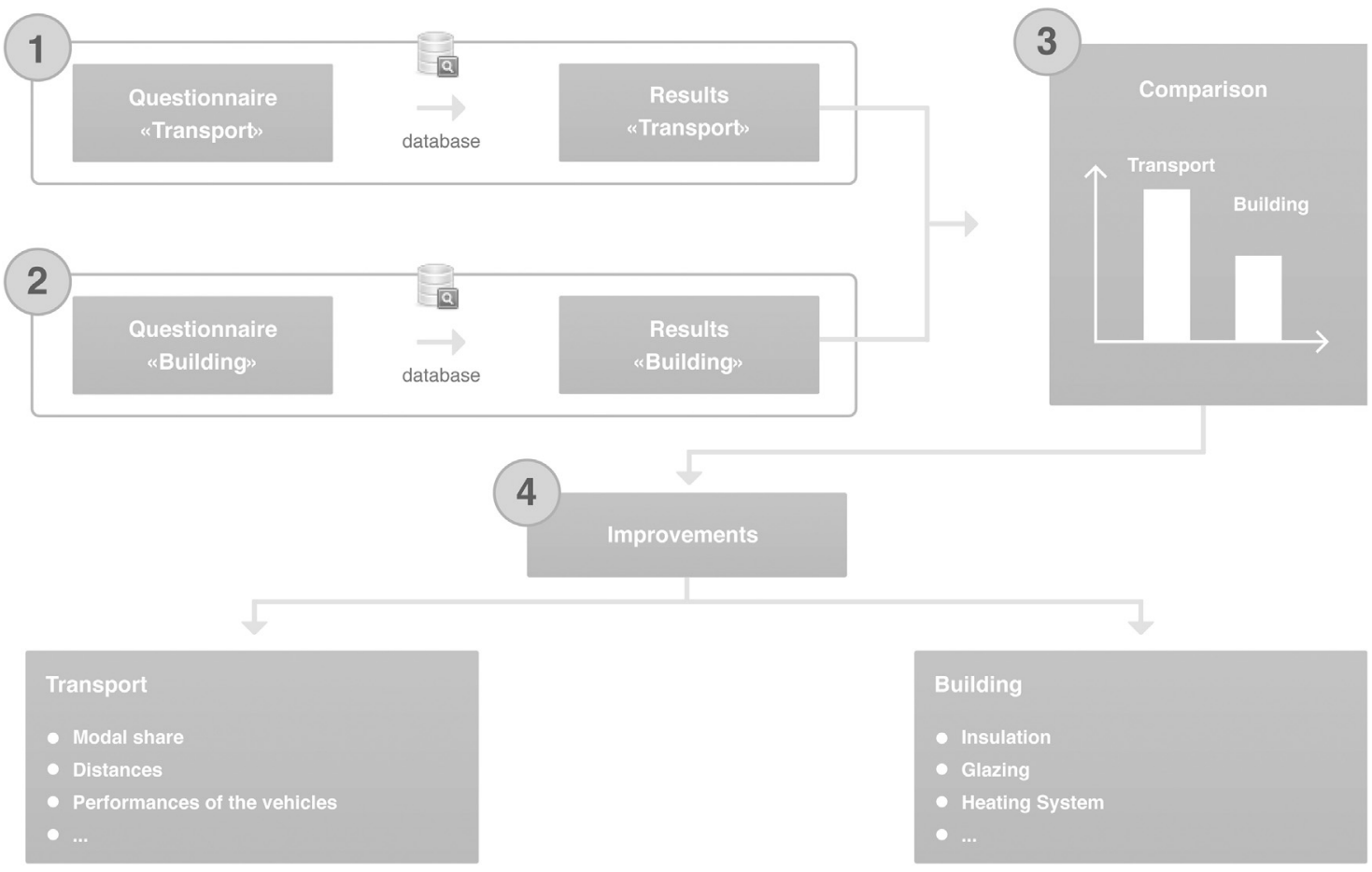

Fig. 2. Structure of the three evaluations.

for the heating of the user's house on the basis of limited information. Completion of the questionnaires is very simple to allow the user to complete them quickly and without specific data.

Two pieces of information related to the location of the house of the user are required to assess the transportation energy consumption (step 1). On this basis, the mean energy consumption for daily mobility, the mean travelled distance from home-to-work and from home-to-school and the mean modal share in the considered district are calculated and provided (algorithms and data are stored in database 1).

Four pieces of information related to the house of the user are required to assess the energy consumption for heating the building (step 2): the house type (detached, semi-detached or terraced house), the heated area of the house in square meters (five ranges are proposed), the date of construction and the heating system (23 possibilities). On this basis, the mean energy consumption (heating and eventually ventilation) is calculated (results of thermal simulations are stored in database 2 and accessible thanks to a unique code linked to the data introduced in the questionnaire by the user). This result is provided along with the results of more efficient houses (reference cases presenting the same characteristics but respecting the current standard for new buildings; retrofitted cases consisting in the same house retrofitted to higher insulation levels).

The comparison sheet (step 3 ) is one of the key elements of the online interactive tool. It allows the user to compare, on an annual basis, the amounts of energy consumption for transportation and for heating the house and thus quickly identify on which sector it is important to act to reduce its energy consumption. Comparison between the annual amounts of energy consumption for transportation and for heating are calculated for a "mean" household, whose composition depends upon the surface area of the house.

The annual energy consumptions for home-to-work and hometo-school travels are calculated by multiplying the total number of home-to-work and home-to-school travels (one way) for all of the workers and students of the household by the corresponding energy performance index and by a standard number of working/school days per year. The annual energy consumption for heating the house is obtained through the database of thermal simulations. Annual $\mathrm{CO}_{2}$ emissions are also provided.

Several improvements (step 4) are finally proposed to the users according to the data introduced in the questionnaire and the result of the assessment. These improvements address both the transportation and the building sectors. Each improvement comprises a brief description and a quantification of the potential energy savings. The proposed improvements include the mode of transportation (modal transfer from car to bus, train or active mode), a reduction in the travelled distances, the performance of the vehicles, car sharing, the level of insulation of the building, the type of glazing and the heating system.

\subsection{The detailed evaluation}

The detailed evaluation allows an individual user (or household) to assess the amounts of energy consumption for daily mobility (numerous purposes of travels and chained trips can be taken into account) and for heating the house of the user more precisely than in the simplified evaluation. The questionnaires are more complex, but the results are closer to the real situation of the user.

The user is first asked to precisely define the composition of the user's household (number of adults and of children) and the transport habits of each member of the household (step 1). For each person, it is necessary to specify the mode of transport (up to two different modes per person can be introduced in the questionnaire), the travelled distance, the number of travels per week and per year. Detailed questions about the consumption of the vehicle, the type of fuel and car sharing are asked if the mode is the car. Instead of providing mean values defined on the basis of national surveys, the energy consumption for daily mobility is thus calculated via Eq. (1) (database 1) and according to the travel characteristics of the user.

The first part of the second questionnaire (step 2) is similar to the simplified questionnaire. A second part allows the user to refine these data by adding information about eventual renovation works. The mean insulation of the envelope can be adapted as well as the insulation of the roof. It is also possible to personalise the choice 

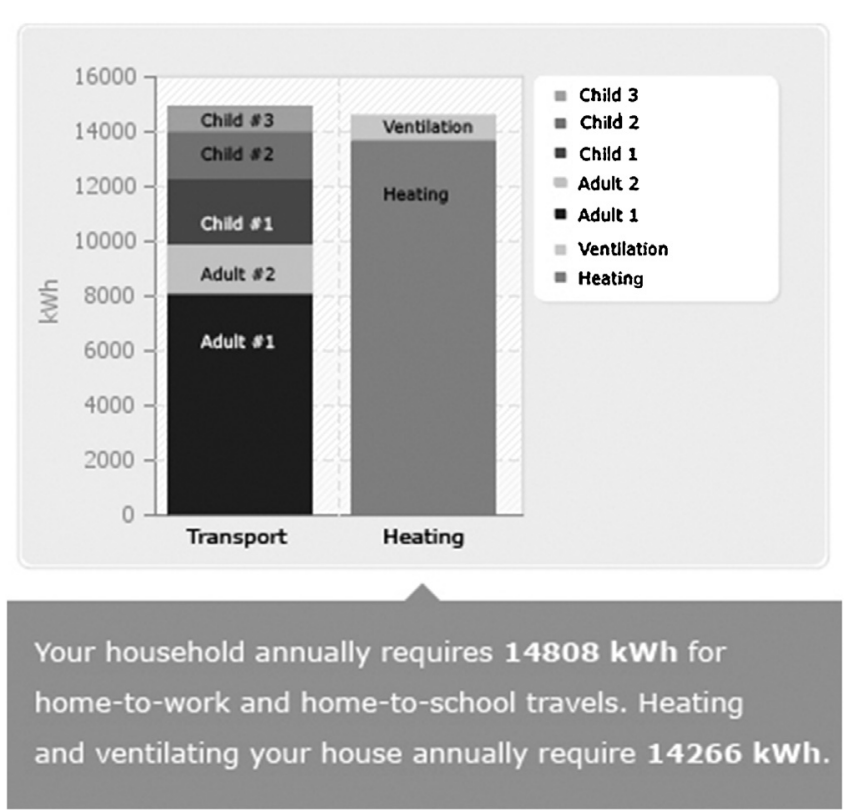

Fig. 3. Example of the results of a comparison between the energy used for transportation and for heating (in $\mathrm{kWh}$ ) for a household consisting of 2 adults and 3 children and for the specific data introduced in the questionnaires.

of glazing (up to triple glazing), the management of the heating system and the characteristics of the ventilation system. Energy consumption for heating, primary energy consumption and $\mathrm{CO}_{2}$ emissions are provided, and the results are then compared with a reference case and with renovated cases consisting of the same house retrofitted to higher insulation levels (database 2).

Just as in the simplified evaluation, the two last sheets (steps 3 and 4) provide the user with a comparison, on an annual basis, of the energy used for transportation and for heating and with the recommendation of several improvements concerning both sectors (Fig. 3). The potential energy savings related to each improvement are proposed and quantified. An example of improvements proposed is provided on Figs. 4 and 5.

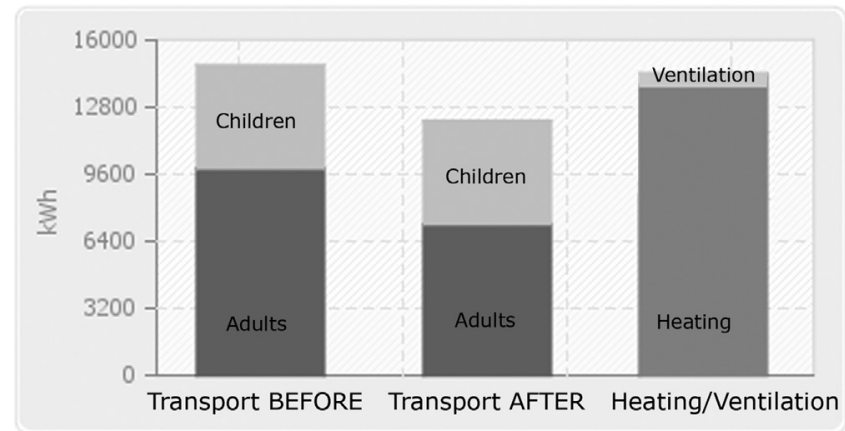

Fig. 5. The impact of one scenario ( $50 \%$ of travels to work by bus, for adult 1 ) on the energy consumption of the household.

\subsection{The neighbourhood evaluation}

The neighbourhood evaluation is dedicated to private developers, local authorities and architects. The neighbourhood evaluation tool allows the user to assess the energy consumption for transportation and for heating houses at the neighbourhood scale. This tool is particularly useful to assess the impact of a future development. Local authorities can also determine the best sites to develop according to the expected amounts of energy consumption for home-to-work and home-to-school travels.

The first questionnaire (step 1) is the same as that in the simplified evaluation, and the energy consumption indexes for one representative worker and one representative student are calculated according to the same method (database 1). The composition of the (future) neighbourhood is added to provide the annual energy consumption for home-to-work and home-toschool travels at the neighbourhood scale. This value is calculated by multiplying the individual index for one worker/one student by the number of workers and students living within the considered (future) neighbourhood and by a standard number of working/school days per year.

As far as heating energy consumption is concerned (step 2), eight pieces of information related to each type of buildings are required, and the entire neighbourhood can be composed of up

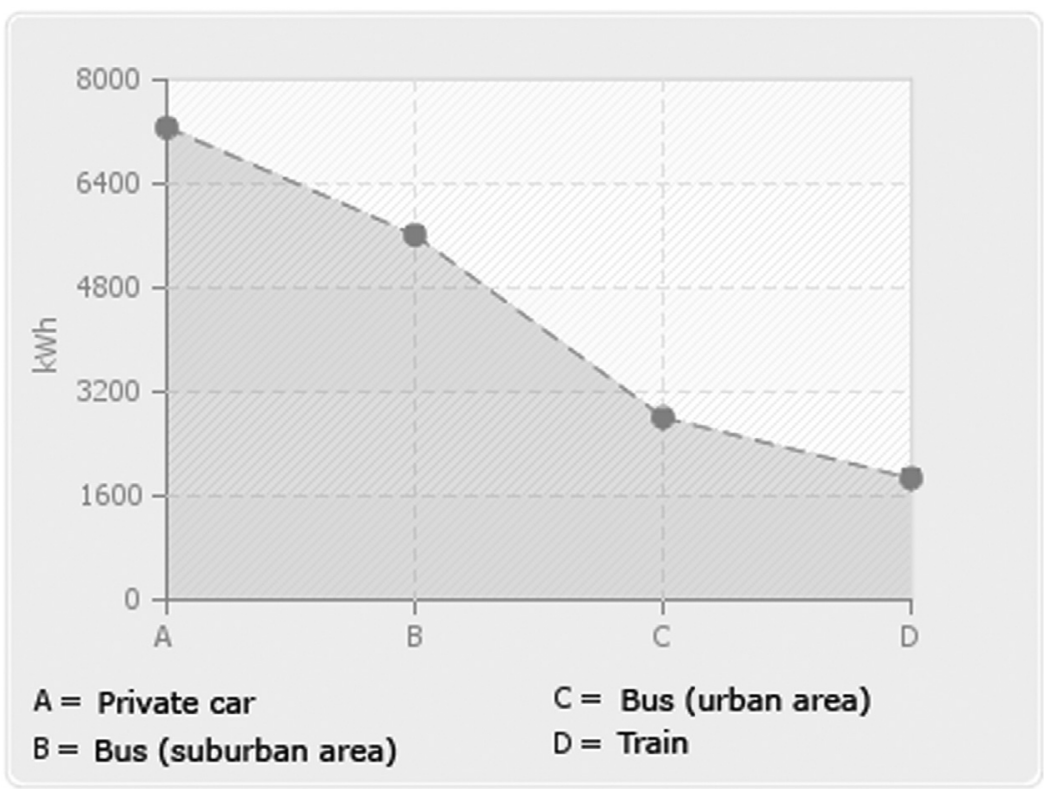

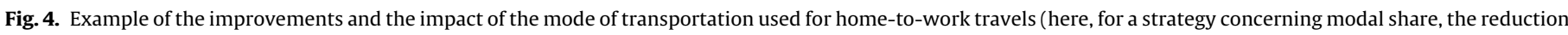
of energy consumption for different modes of transportation for adult 1). 
to four types of buildings. The types of buildings are defined as: (1) a house type (detached, semi-detached or terraced house), (2) a heated area of the type in square meters (17 ranges are proposed), (3) the date of construction, (4) the insulation of the roof, (5) choice of glazing (up to triple glazing), (6) the management of the heating system, ( 7 ) the heating system (23 possibilities) and ( 8 ) the number of units representative of this type of buildings in the neighbourhood. The energy consumption of buildings and the primary energy consumption for heating at the neighbourhood scale are calculated by adding the results from the energy consumption analysis for each type of house according to their distribution in the neighbourhood, as mentioned in the questionnaire (database 2 ). The results are compared with a "reference" neighbourhood composed of the reference buildings of each type. The user can compare the assessed neighbourhood with the same neighbourhood that is following the current standard for new buildings and with several cases retrofitted to higher energy-efficient levels (low energy, very low-energy and passive standards).

Just as in the two previous evaluations, the two last sheets (steps 3 and 4) provide the user with a comparison, on an annual basis, of energy used for transportation and for heating and with the proposition of several improvements concerning both sectors, but here, the results are at the neighbourhood scale. The potential energy savings related to each improvement are quantified for the entire district.

\subsection{The specification sheets}

Eighteen specifications sheets complete the website by providing the user with facts about energy efficiency. These sheets are classified around four main themes: (1) general and urban sprawl; (2) energy efficiency in the transportation sector (mobility); (3) energy efficiency in the building sector (building) and (4) energy efficiency at the district scale (urban form).

These specification sheets not only present the methods, assumptions and data used in the online interactive tool but also practical recommendations to improve energy efficiency at the household scale and at the neighbourhood scale. Life-cycle assessments of buildings, the importance of the heating system, the impact of location on mobility patterns and the use of renewable energy sources are also investigated.

\subsection{Usability of the tool}

To have a first idea of the relevance and the applicability of the first version of this interactive tool (the tool is currently improved and completed (e.g., to take into account the production of energy thanks to renewable sources, to include economic constraints) in a new research project (SOLEN - Solutions for Low Energy Neighbourhoods), several test-sessions were organised with different focus groups (around 100 students from secondary schools, students in urban planning, regional and local administrative officers in charge of energy, sustainable buildings and/or urban planning, architects, researchers in sustainable architecture and a non-specialised audience). The resulting feedback was quite positive, especially from government officers who lack evaluation tools that address both the transportation and building sectors. The nonspecialised audience is particularly interested in the results that highlight the impact of the location of the house on transportation energy consumption and provide a comparison of transportation energy consumption with building energy consumption as well as the results relating to the energy efficiency of several retrofitting works (especially the insulation of the roof, the change of the glazing and the replacement of the heating system). Two workshops dedicated to professionals (60 people) were also organised, and several general-interest papers were published to ensure wide distribution of the tool. The tool is currently online and used by citizens (we register approximately 400 visits a month on the website during a 6-month testing period, from July 2012 to December 2012).

This information, currently used to improve and complete the tool, do not constitute a true validation of the tool. To address this issue, a usability testing [e.g., 27, 51] will be organised, in 2015, at the end of the new research project (Solutions for Low Energy Neighbourhoods - SOLEN) to concretely identify the impact of the online interactive tool on decision making as well as on the everyday behaviour of users and their decisions to perform retrofitting works.

The research teams currently continue to use this online interactive tool in numerous actions related to outreach and to the formation of architects and other professionals.

\section{Discussion}

Like any other scientific work, this online interactive tool suffers from several limitations. Currently, the results provided in two of the three evaluations (the simplified evaluation and the neighbourhood evaluation) only take into account the energy consumption for home-to-work and home-to-school travels. Regarding building energy consumption, only heating and ventilation are considered. The building database considers only suburban types of buildings. These limitations will be addressed soon by the new SOLEN research project that will not only account for rural and urban types of buildings but also address energy consumption for all purposes of travel. The energy consumption for hot water and appliances and the use of various renewable energy sources (solar photovoltaic, solar thermal, small wind turbines, heat pumps, CHP) will also be integrated in this project and in the updated version of the online interactive tool (available by 2015). A quick assessment of the economic advantage of each improvement proposed will complete the updated tool. A more prospective approach of transportation energy consumption is currently under development. This complementary approach could allow the comparison of the accessibility of different houses and neighbourhoods and is more specifically addressed to local and regional public authorities.

The online interactive tool is only available for Wallonia (Belgium) (in French) because we used local data. However, as far as the reproducibility of the approach presented in this paper is concerned, the methods used to develop the tool are flexible and parameterized what makes applicable to many other areas in Europe and beyond by adjusting its parameters, such as those relating to climate, vehicle performances or the building characteristics. Note also that surveys similar to the one used on our paper are for example carried out by the French National Institute of Statistics (INSEE) in France or the Office for National Statistics (ONS) in the United Kingdom.

Finally, this parameterization of the methods used to build the databases will also allow the research team to continually update and improve the tool, namely by taking into account changes and improvements in actual technologies and behaviours (e.g., the integration of electric cars by calculating a new consumption factor for these cars (see Eq. (1)), the integration of new or more efficient heating system by adapting the related factors, a change in the use of public transportation by adapting the occupation rate).

\section{Conclusion}

This paper presented a new online interactive tool (www.safe-energie.be) that enables Walloon (Belgium) citizens, local authorities and developers (1) to assess the sources of energy consumption for daily mobility and for heating buildings at the individual, household and neighbourhood scales; (2) to 
compare these different energy consumption sources and (3) to determine relevant and personalised recommendations to reduce their energy consumptions. This online interactive tool represents the main results (over 180,000 thermal simulations and powerful algorithms) of an important three-year scientific research project dedicated to energy efficiency, in Wallonia, that is accessible to a large non-specialised audience, which is crucial in the scope of the sustainable development. This online interactive tool allows, in particular, the enhancement of public awareness, not only of the importance of retrofitting the existing building stock but also of the major importance of the location of a house/neighbourhood and transportation energy consumption for daily travels.

\section{Acknowledgements.}

This research study was funded by the Walloon region (Belgium) under the "Suburban Areas Favouring Energy efficiency" project (SAFE). We thank Julien Winant for the web development of the tool and the numerous persons that agreed to participate to the test sessions and provide us with useful feedback on the tool.

\section{References}

[1] M. Maïzia, C. Sèze, S. Berge, J. Teller, S. Reiter, R. Ménard, Energy requirements of characteristic urban blocks, Proceedings of CISBAT 2009 Scientific Conference on Renewables in a Changing Climate, Lausanne, Switzerland, 2009, 439-44.

[2] CEC, Green Paper on Energy Efficiency or Doing More With Less, Report CEC COM (2005)265, Commission of the European Communities, Belgium, 2005.

[3] European Commission, European Energy and transport - Trends to 2030, European Commission, 2008.

[4] H. Hens, W. Parijs, M. Deurinck, Energy consumption for heating and rebound effects, Energy and Buildings 42 (1) (2010) 105-110.

[5] L. Perez-Lombard, J. Ortiz, C. Pout, A review on buildings energy consumption information, Energy and Buildings 40 (3) (2008) 394-398.

[6] V.A. Dakwale, R.V. Ralegaonkar, S. Mandavgane, Improving environmental performance of building through increased energy efficiency: a review, Sustainable Cities and Society 1 (4) (2011) 211-218.

[7] G. Escriva-Escriva, C. Alvarez-Bel, E. Penalvo-Lopez, New indices to assess building energy efficiency at the use stage, Energy and Buildings 43 (2-3) (2011) 476-484.

[8] E. Gratia, A. De Herde, A simple design tool for the thermal study of dwellings, Energy and Buildings 34 (2002) 411-420.

[9] E. Gratia, A. De Herde, A simple design tool for the thermal study of an office building, Energy and Buildings 34 (2002) 279-289.

[10] E.M. Ryan, T.F. Sanquist, Validation of building energy modelling tools under idealized and realistic conditions, Energy and Buildings 47 (2012) 375-382.

[11] P. Tuominen, R. Holopainen, L. Eskola, J. Jokisalo, M. Airaksinen, Calculation method and tool for assessing energy consumption in the building stock, Building and Environment 75 (2014) 153-160, http://dx.doi.org/10. 1016/j.buildenv.2014.02.001.

[12] K. Steemers, Energy and the city: density, buildings and transport, Energy and Buildings 35 (2003) 3-14

[13] G. Ratti, N. Baker, K. Steemers, Energy consumption and urban texture, Energy and Buildings 37 (2005) 762-776.

[14] P.J. Jones, S. Lannon, J. Williams, Modeling building energy use at urban scale, in: Proceedings of the 7th International IBSPA Conference, Rio de Janeiro, Brazil, 2001, pp. 175-180.

[15] A.F. Marique, S. Reiter, A method to evaluate the energy consumption of suburban neighbourhoods, HVAC\&R Research 18 (2012) 88-99.

[16] S. Reiter, A.F. Marique, Toward low energy cities: a case study of the urban area of Liège, Journal of Industrial Ecology 16 (2012) 829-838.

[17] R. Ewing, R. Cervero, Travel and the built environment: a meta-analysis, Journal of the American Planning Association 76 (2010) 265-294

[18] P. Newman, J.R. Kenworthy, Sustainability and cities: overcoming automobile dependence, Island Press, Washington DC, 1999.

[19] M. Breheny, The compact city and transport energy consumption, Transactions of the Institute of British Geographers 20 (1995) 81-101.

[20] M. Boarnet, R. Crane, Travel by design. The influence of urban form on travel, Oxford University Press, New-York, 2001

[21] K. Boussauw, F. Witlox, Introducing a commute-energy performance index for Flanders, Transportation Research Part A 43 (2009) 580-591

[22] A.F. Marique, S. Reiter, A method for evaluating transport energy consumption in suburban areas, Environmental Impact Assessment Review 33 (2012) 1-6.

[23] O.G. Santin, L. Itard, H. Visscher, The effect of occupancy and building characteristics on energy consumption for space and water heating in Dutch residential stock, Energy and Buildings 41 (2009) 1123-1232.
[24] T. de Meester, A.F. Marique, A. De Herde, S. Reiter, Impacts of occupant behaviours on residential heating consumption for detached houses in a temperate climate of the northern part of Europe, Energy and Buildings 57 (2012) 313-323.

[25] EPBD, Directive 2001/91/EC of the European Parliament and of the Council of 16 December 2002 on the energy performance of buildings, Brussels, 2002.

[26] C. Tweed, P. Jones, The role of models in arguments about urban sustainability, Environmental Impact Assessment Review 20 (2000) 277-287.

[27] S. Attia, E. Gratia, A. De Herde, J.L.M. Hensen, Simulation-based decision support tool for early stages of zero-energy building design, Energy and Buildings 49 (2012) 2-15.

[28] L.R. Glicksman, Promoting sustainable buildings, HVAC\&R Research 9 (2003) 107-109.

[29] M. Praznik, V. Butale, Z. Senegacnik, Simplified evaluation method for energy efficiency in single-family houses using key quality parameters, Energy and Buildings 67 (2013) 489-499.

[30] D. Reilly, A. Duffy, D. Willis, M. Conlon, Development and implementation of a simplified residential energy asset rating model, Energy and Buildings 65 (2013) 159-166

[31] H.X. Zhao, F. Magoules, A review on the prediction of building energy consumption, Renewable and Sustainable Energy Review 16 (6) (2012) 3586-3592.

[32] J. O'Looney, Sprawl decisions: a simulation and decision support tool for citizens and policy makers, Government Information Quarterly 18 (4) (2001) 309-327.

[33] A.F. Marique, S. Dujardin, J. Teller, S. Reiter, School commuting: the relationship between energy consumption and urban form, Journal of Transport Geography 26 (2013) 1-11.

[34] A.F. Marique, S. Dujardin, J. Teller, S. Reiter, Urban sprawl, commuting and travel energy consumption, Proceedings of the Institution of Civil Engineers, Energy 166 (2013) 1-13.

[35] (Ed.), E. Van Hecke (Ed.), I. Thomas (Ed.), B. Merenne-Schoumaker (Ed.), M. Beelen, J.M. Halleux, J.M. Lambotte, G. Rixhon, Le mouvement pendulaire en Belgique: les déplacements domicile-travail, les déplacements domicileécole. Enquête Socio-économique 2001. Monographies (n(10) (Traduit en néerlandais). Bruxelles, Belgique: SPF Economie, PME, Classes moyennes et Energie, 2009.

[36] ICEDD, Bilan énergétique wallon 2007, Consommations du secteur du logement 2007. MRW, Direction générale des technologies, de la recherche et de l'énergie - Conception et réalisation ICEDD asbl, Namur, Belgium, 2007.

[37] CEEW, Rapport analytique sur l'état de l'environnement wallon 2006-2007, MRW - Direction générale des ressources naturelles et de l'environnement. Rapport D/2007/5322/45, Namur, Belgium, 2007.

[38] C. Kints, La rénovation énergétique et durable des logements wallons. Analyse du bâti existant et mise en évidence des typologies de logements prioritaires Architecture \& Climat, UCL, Ministère de la Région Wallonne (MRW-DGTRE) International Energy Agency, Solar heating \& cooling of Task 37 and Federal Science Policy, project LEHR (www.lehr.be), 2007.

[39] A. De Herde, M. Bodart, Les conclusions de Pléiade, Université catholique de Louvain, Belgium, 1994.

[40] C. Massart, A. De Herde, Conception de maisons neuves durables, Elaboration d'un outil d'aide à la conception de maisons à très basse consommation d'énergie, Architecture et Climat - UCL, financé par Service Public Wallonie DG04 Département de l'Energie et du Bâtiment durable, 2010.

[41] NBN, NORME NBN D50-001, Dispositifs de ventilation dans les bâtiments d'habitation, Brussels, Belgium, 2008.

[42] NBN, NORME NBN B 62-002, Performances thermiques de bâtiments, Calcul des coefficients de transmission thermique (valeurs U) des composants et éléments de bâtiments, Calcul des coefficients de transfert de chaleur par transmission (valeur HT) et par ventilation (valeur Hv), Brussels, Belgium, 2008.

[43] A.M. Jones, TAS, Software package for the thermal analysis of buildings, EDSL Ltd, United Kingdom, 2010.

[44] IWEC, Weather Files (International Weather for Energy Calculations), ASHRAE, Atlanta (USA), 2009.

[45] C. Delmotte, Réglementation sur la performance énergétique des bâtiments: du nouveau à Bruxelles et en Wallonie, Les Dossiers du CSTC 4 (2010).

[46] PEB, Décret wallon sur la performance énergétique des bâtiments, Annexe I: Méthode de détermination du niveau de consommation d'énergie primaire des bâtiments résidentiels, and Annexe III: Valeurs U maximales admissibles ou valeurs R minimales à réaliser, 2007.

[47] W. Feist, Logiciel de conception de maison passive PHPP2007, Passivhaus Institut, Darmstadt, 2007.

[48] Energie+, Energie+ version 6, Architecture et Climat, Université catholique de Louvain (Belgique), réalisé avec le soutien de la Wallonie - DGO4 - Département de l'Energie et du Bâtiment Durable. Disponible sur: http://www.energiepluslesite.be, 2010

[49] IBGE, Choisir le meilleur mode de production de chaleur, Guide pratique pour la construction et la rénovation durables de petits bâtiments, Recommandation pratique ENE 14, IBGE, 2010.

[50] J. Nielsen, Chapter 6, in: Usability Engineering, 2nd ed., Academic Press, San Diego, 1994, pp. 165-206.

[51] B. Peuportier, Bancs d'essai de logiciels de simulation thermique, Proceedings of Journée Thématique SFT-IBPSA. 